\title{
THE CONCEPTUAL FRAMEWORK OF A KNOWLEDGE-BASED PERFORMANCE MANAGEMET SYSTEM
}

\author{
Dermawan Wibisono \\ School of Business and Management, Institute of Technology Bandung (ITB) \\ Mohammed K. Khan \\ School of Engineering, Design and Technology, University of Bradford, England (UK)
}

Designing a Performance Management System (PMS) is an integral part of management control systems. This paper presents a hybrid framework for the design of a PMS for the Indonesian context, and the tailor-made design is expected to overcome the shortcomings of earlier models. The present hybrid PMS model seeks to improve the earlier research models using the following novel approaches: (1) implementation of a Knowledge-Based (KB) expert system, (2) Gauging Absences of Prerequisite (GAP) analysis, and (3) Analytical Hierarchy Process (AHP) methodology in an integrated KBPMS. The paper shows that the present hybrid (KBAHP-GAP) approach to developing a PMS model is a realistic methodology. The combination of the KB-AHP-GAP approach allows detailed benchmarking of the PMS existing in an Indonesian company. Furthermore, this approach can assist in identifying and prioritising the key decisions that need to be executed to overcome the existing PMS shortcomings.symbiotic strategic alliances. Conversely, affiliate firms prefer competitive strategic alliances with competitors when they are not dependent on the parent firm.

Keywords: analytical hierarchy process (AHP); expert system; GAP analysis; knowledge-based (KB); performance management system (PMS) 


\section{Introduction}

Companies nowadays realize that the need for accurate and comprehensive information on their activities is of crucial importance. This is because, as Sousa et al. (2005), Gosselin (2005) and Medori and Steeple (2000) have indicated, firms need to have a number of critical components in order to be classified as World Class Manufacturers (WCM); one of the ingredients is having an appropriate Performance Management System(PMS). Throughout the 1990s, various novel frameworks were derived by organizations to select and implement measures, such as SMART (Cross and Lynch 1989), Performance Measurement Questionnaire (PMQ) (Dixon et al. 1990), Performance for World Class Manufacturing (PWCM) (Maskell 1991), Vital Signs (Hronec 1993), the Balanced Scorecard (BSC) (Kaplan and Norton 1996) and the Performance Prism (Neely et al. 2002). However, as Zairi and Letza (1994) have observed, research on the area of performance management has not yielded solid findings, and this in fact remains a challenge. Neely and Bourne (2000) support this argument through their research findings, showing that approximately 90 percent of managers fail to implement and deliver their organizations' strategies by the performance management applied. They argue that this failure is mainly due to the busi- ness performance itself being a multifaceted concept that needs a different type of PMS. Furthermore, as noted by Sellenheim (1991) and Ljungberg (1994), methods for developing and implementing detailed measures, adapted to the environment of a specific company, are seldom described in details. In addition, the difference in vision and mission relates to the existence of a firm in the nation in which the company is a state-owned or private company.

Summarized in the Table 1 are the previous frameworks of PMS and the proposed model that tries to fulfil some gaps left by those frameworks. From Table 1, it can be seen that several gaps still exist which require improvement in the PMS model, including the implementation of knowledge-based approach, the support by software to make decision-making, and the implementation of Analytical Hierarchy Approach (AHP).

It has been known among experts in the area of performance management system that BSC is the most popular approach around the world although some critiques on the approach still prevail. The second approach, which is also popular for Indonesian companies, is MBNQA by which some countries like Singapore, Australia, and Europe have modified and adapted into their country specific settings. 
Wibisono \& Khan -The Conceptual Framework of a Knowledge-Based Performance Management System

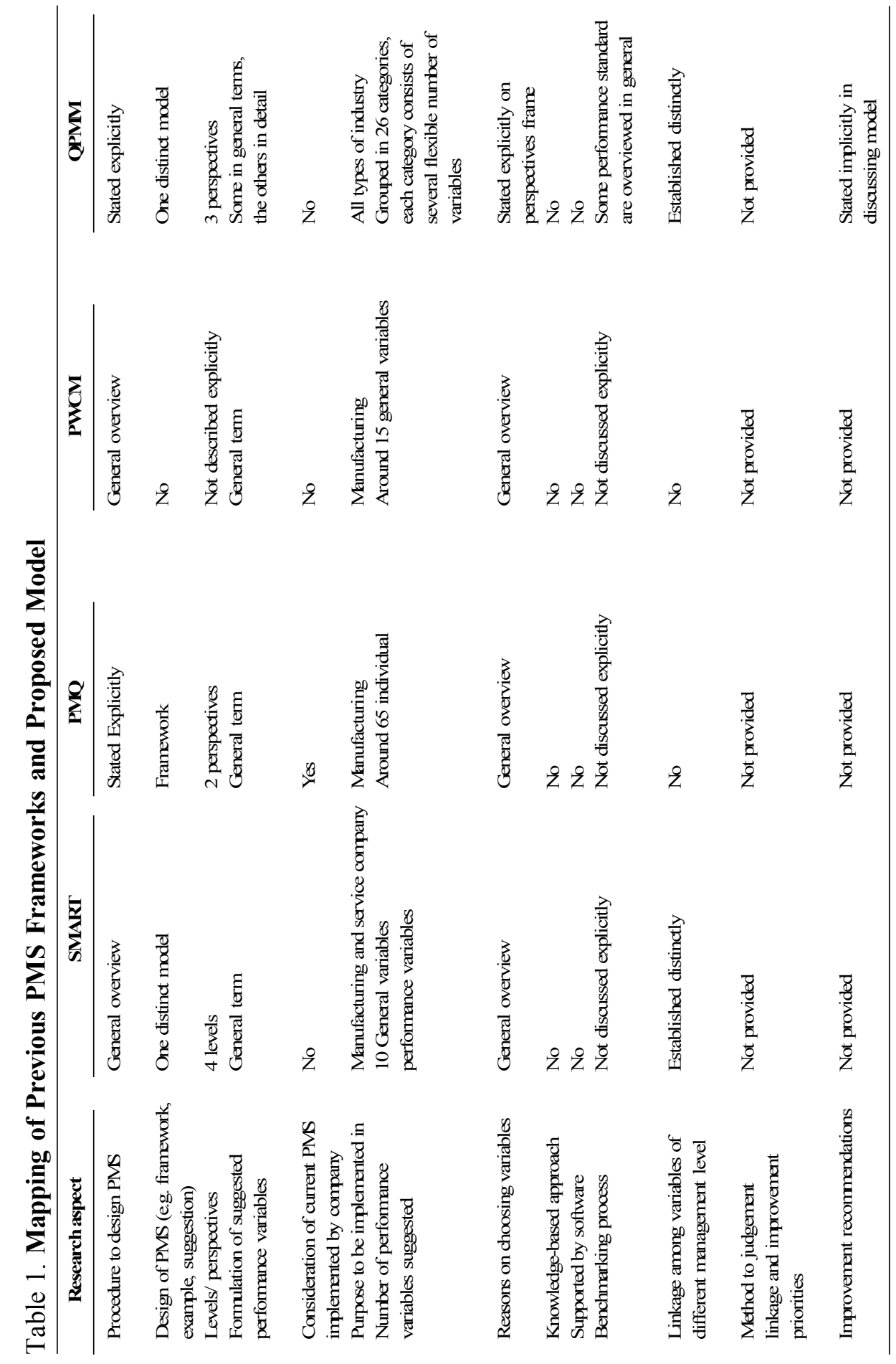


Gadjah Mada InternationalJournal of Business, September-December 2010, Vol.12, No.3

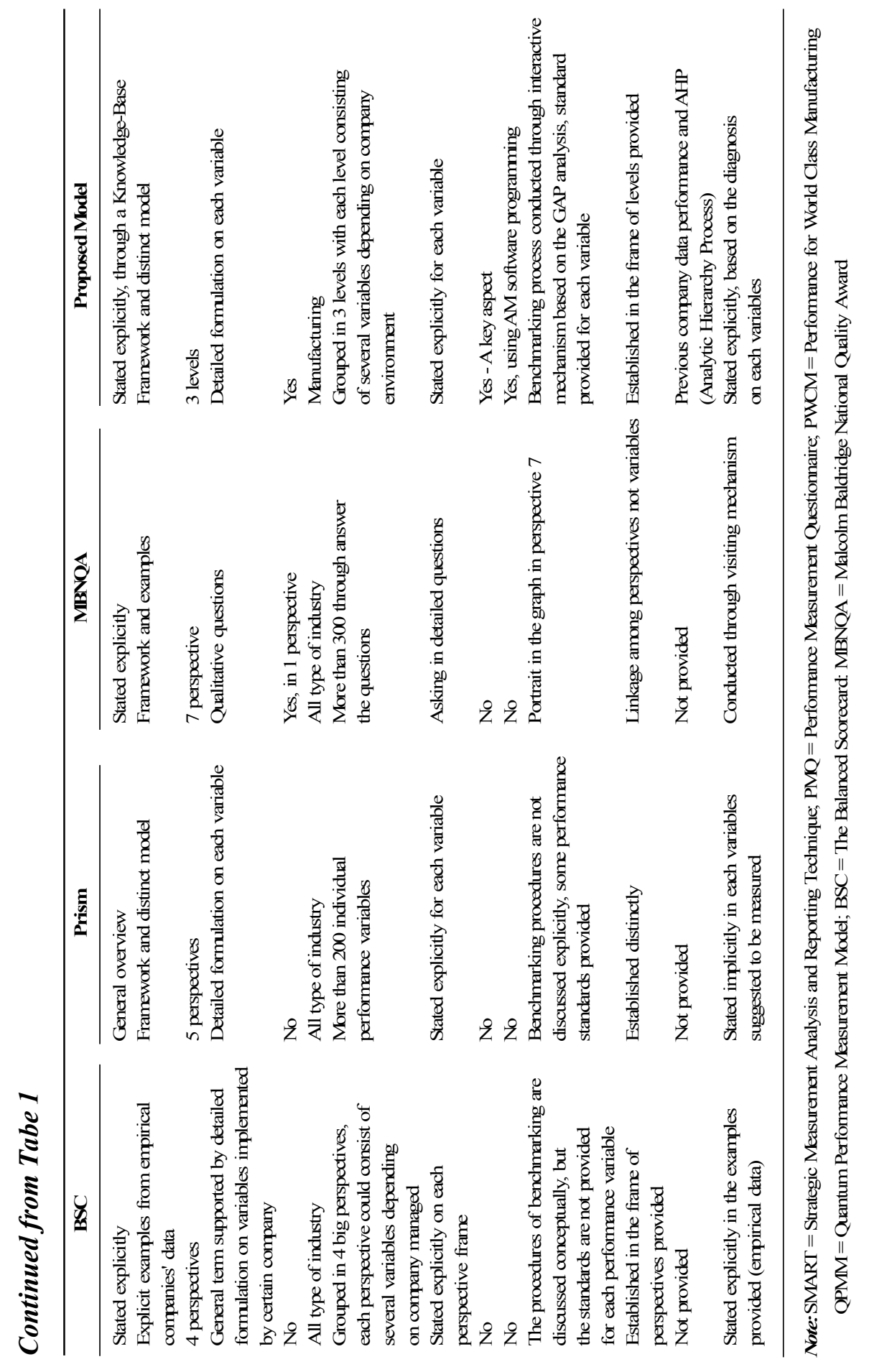

396 
Wibisono \& Khan -The ConceptualFramework of a Knowledge-Based Performance Management System

In Indonesia, some companies still adopt this technique 100 percent as the original, and hence are faced with difficulties implementing it mostly because of qualitative questions to be answered while only a few experts can help the firms. These two global perspectives are potentially implemented but need further adjustments and improvisations, such as issues regarding which performance indicators to be used, how the benchmarking process is done, and how these approaches can be suitable for non-profit organizations. This evidence basically proves that performance management system needs a contextual approach. For instance, Indonesian firms may have different cultures and business mechanisms from Western or Japanese companies. For certain companies, such as the state-owned enterprises, they have responsibilities for not only making profit but also contributing to the development of social welfare. Therefore, the different backgrounds possessed by the Indonesian companies clearly require a tailor-made approach of PMS which is more workable in the Indonesian environment. This paper purports to answer the need, and presents a novel approach to the design of PMS through the application of Knowledge-Based (KB) expert system that has not been carried out in the past.

The KB approach is selected based on the following rationales. Firstly, a large number of performance variables are usually involved in the successful implementation of PMS and the relationships among them are quite com- plex. Secondly, the priorities for improving performance variables need supporting tools to keep the validity and consistency of decision-making. Thirdly, the benchmarking process in figuring a company's competitiveness also has to be facilitated by appropriate tools. These circumstances render the selection of the proper methodology and its implementation being quite a challenging task for practitioners in the industry.

The KB system is applied to make the PMS valid, consistent, and practical for implementation (Wibisono 2003). Firstly, the KB system application is not only based on the theoretical basis, but also on the feedback from practitioners in Indonesia, such as from PT Telkom, PT Pupuk Kaltim Group, PT Angkasa Pura II, PT Pindad, PT Pertamina, and many others. To those big companies, it is extremely complicated to implement PM without the support of KB system since the application of KB system provides the opportunity to interact with users in an appropriate manner and to assist in the decision-making process. Secondly, the tedious and cumbersome calculations involved in performance variable formulas and the benchmarking process can be easily and accurately incorporated within the rule-based expert system structure. Thirdly, by incorporating the explanatory features, the $\mathrm{KB}$ system can be harnessed as a learning device for all members of the organization. These features of KB system, coupled with the analysis of qualitative features of PMS through embed- 
ded Gauging Absence of Prerequisite (GAP) analysis and Analytic Hierarchy Process (AHP) approaches, will make the hybrid KBPMS model of KB-AHP-GAP analyses a real, practical and effective decision-making tool for practitioners.

\section{The Conceptual Frameworks of PMS}

The previous section has surveyed a number of PMS frameworks, introduced their benefits as well as limitations. Compared to the previous frameworks, the proposed KBPMS model in this study is new in a number of key ways, thanks to the use of an interactive methodology regarding the $\mathrm{KB}$ system as a decision-making tool. The implementation of GAP analysis together with the AHP approach in an integrated KBPMS model covers all organizational levels, and provides the exact analysis of the present PMS against a benchmark.

In developing the PMS, previous researchers began by identifying the characteristics of 'reliable' measurement systems, for which some provide the characteristics explicitly while others imply them by criticizing the financial performance measurements [see for examples: Dixon et al. (1990), Maskell (1991), Medori (1998) and Letza (1997)]. Even though there are some differences in terminologies and scopes of the characteristics proposed by these studies, they can be condensed into a set of general principles as summarized below. These principles are utilized as the basic thoughts for developing the PMS in this study:

1. A PMS should relate the performance of shop floor to company strategy.

2. A PMS should consist of a set of well-defined and measurable criteria. Even though previous studies implemented a vast array of variables, there is a general agreement as to how to choose the 'appropriate' variables as summarized below:

a. The chosen performance variables must be easily understood and represent the system they try to measure.

b. The 'KISS' (Keep It SimpleStupid) principle should be applied. Simple should also represent a 'comprehensive' measurement of the right thing. This reinforces the need for identifying key technical indicators and the importance of comprehensive summary measures.

c. In choosing performance variables, care should be given to avoid two particular problems: 'false alarm' and 'gap'. Schmenner and Vollmann (1994) define the term 'false alarm' to be the use of wrong measures to motivate managers, so they spend time improving something that has few positive consequences to the company, and perhaps even involve some harmful consequences. The term 'gap' refers to a fail- 
Wibisono \& Khan -The ConceptualFramework of a Knowledge-Based Performance Management System

ure to include a necessary measure so that something important for the company stays neglected.

3. The standard of performance for each criterion is very important. It should be complemented by procedures to compare actual performance achieved to the standard provided.

4. A PMS should foster improvement rather than just monitor performance. The system should focus on how the company is currently performing, and indicate where it needs improvement. Manufacturing performance management as a measure of progress needs to have a reference state against which management is evaluated.

5. A PMS should provide information on a timely basis. The aim should be to provide feedback as close to the event as possible. Reporting 'on a timely basis' usually means 'when feasible.' Timeliness is essential in the application of PMS since competition among companies is a dynamic environment. Long report lead times render useful information obsolete, which greatly reduces its value as a basis for corrective actions. In general, the greater the delay of reported information, the higher is the cost.

Referring to these principles of developing the PMS and considering the steps of designing a PMS, there are three salient stages that we go through in the development of the KBPMS Model:(1)Basic Information, (2) Core of Performance Management, and (3) Performance Management Mechanisms. Within these three features of the conceptual model, the KB expert system is harnessed as the foundation, as depicted in Figure 1 and described in details in the following sections.

\section{Stage 1}

Figure 1 shows that in the Basic Information stage, there are three major sets of information that need to be considered:(1) Company Environment Information, (2) Financial and Market Information and (3) Product or Service Information. The objective of the Company Environment Information is to position the area in which the company is currently competing.

The reasons for considering the company's Financial and Market Information is that financial performance indicates how the firm is presently managed with respect to efficiency and effectiveness financially (Kaplan and Norton 1996). While Market Share reflects how competitive the company's products and services are, it also provides an indication of customer satisfaction vis-a-vis its competitors (Centre for Business Performance 1999).

Since the Product and Service Information is a backbone of the company's competitiveness, the information on the products and services is absolutely crucial. For all intents and 
Gadjah Mada InternationalJournal of Business, September-December 2010, Vol.12, No. 3

Figure 1. The Conceptual Framework of a PMS

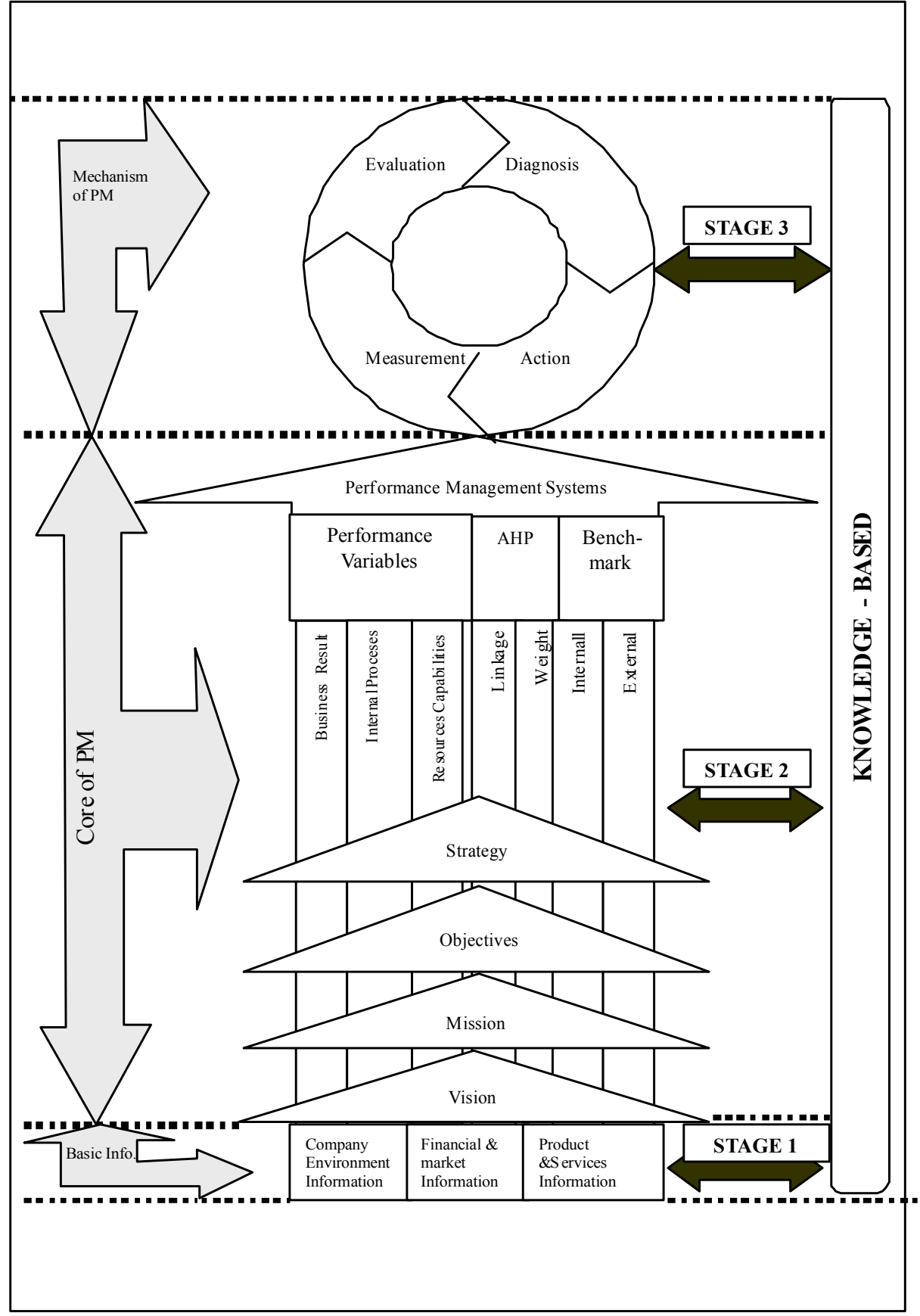

Source: Wibisono (2003) 
Wibisono \& Khan -The ConceptualFramework of a Knowledge-Based Performance Management System

purposes, it is this aspect of the company that the customer receives.

\section{Stage 2}

In the Core of Performance Management aspect, there are several important pieces of information that need to be considered, such as company statements, performance variables, the linkages among performance variables, the weight of each variable relative to the company's performance, and the performance standard of each variable.

Since company statements such as the company's strategy, vision, mission, and objectives determine the future direction, it is therefore important to explore whether the company not only has these statements but also communicates them to all employees at all levels. All company statements should become a 'compass' for guidance in determining performance variables. This is based on the argument that all performance variables used in thePMS have to be aligned with the company's strategy, vision, mission, and objectives (Kaplan and Norton 1996).

From Figure 1, it can be seen that there are three different groups of company performance variables related to the management responsibility: (1) Business Results, (2) Internal Processes, and (3) Resource Capabilities. Each of these three groups consists of several performance variables. The most critical aspect in this stage is to determine which performance variables are most appropriate to the com- pany. Within the company's environment, managers can lead the company to become a competitive weapon with outstanding achievements of one or more of performance measures. However, managers need to know: What must we be especially good at: quality, lead times, cycle times, productivity, delivery, product flexibility, volume flexibility, minimum changing schedules, rework levels or other measures? Choosing just a single variable will misrepresent the overall company performance, whereas using all the possible variables may represent the real performance but will be very complex. In many cases, performance against some variables may be adequately represented by the measurements of others (Hayes and Pissano 1996). It is impossible to measure every aspect of the company because measurement systems incur real costs, both obvious and covert. Therefore, choosing several key variables that most represent performance is a critical step in developing the key performance indicators.

Referring again to Figure 1, the AHP is embedded in the system for determining quantitative and qualitative linkage patterns among performance variables in the Business Results, Internal Processes and Resource Capabilities. These linkages are important to determine the cause and effect among performance variables in the different levels and to know the improvement priority that should be taken among performance variables in the same level. 
The essence of Benchmarking is to encourage continuous learning and to lift the organization to a higher competitive level. Benchmarking is not a means of winning at any cost, but a legitimate, systematic, overt and ethical process of bringing about effective competitiveness (Zairi 1998). It is concerned more with finding out ideas on managing processes, and thereby achieving superior performance rather than gathering sensitive information on costs, pricing, and effectiveness (Zairi 1998):

- It is a good strategic planning method, and sets credible targets that can be achieved.

- It exposes the organization to contemporary practices by instigating a continuous learning process, and thus can assist in the development of cultures based on change and continuous improvement.

- It is an extremely sound methodology for people education, involvement and empowerment, and in optimizing their creative potentials in the area of innovativeness.

- It has increased general awareness of costs and performance of products and services in relation to those of competitors.

- It is a powerful methodology for developing winning strategies, and a precise way of measuring gaps in performance

\section{Stage 3}

Figure 1 also depicts the Mechanisms of Performance Management aspect, comprised of four main steps: (1) Measurement, (2) Evaluation, (3) Diagnosis and (4) Action.

Performance Measurement has been implemented by companies. However, Performance Measurement often becomes a routine activity without any determined strategy for the required follow-up actions. The results of performance measurement tends to give an insight into the area where the actual performance is worse than expected; however, it does not give insights into why the actual performance differs from the expected, nor does it inform on how one can improve the actual performance. It is apparent that performance measurement does not automatically give an answer to the question, "how good the actual performance is," neither does it give suggestions to where performance improvement is possible (Stoop 1996). Performance measurement, thus, is a starting point for further analysis. Often in practice, qualitative explanations are given which might explain the performance deviations. Although these explanations may sound very reasonable, they are usually very subjective and based on intuitive feelings (Kaplan and Norton 1996).

Performance Evaluation is the assessment of a possible situation in comparison with plans and/or standard previously set as a target. There are two ways to set a performance target: internal and external standards. The first target could be to monitor internal competitiveness in terms of continuous improvement. The most 
Wibisono \& Khan -The ConceptualFramework of a Knowledge-Based Performance Management System

important thing in deciding an internal target is that it should be realistic and challenging; if there is no drive for improvement, people will not easily think of ways to improve their performances (Hayes and Pissano 1996). The internal benchmark could be conducted based on the comparison to the best previous performance, the technical standard, the other departments in the company, the average in a certain period, or the last period's performance. The external target is predicated on the benchmarking of best practices in a similar industry, industry benchmarking, or current competitors. This target is pivotal since the implementation based merely on internal targets can be meaningless if, over time, the competitors are getting further ahead.

Performance Diagnosis is defined as the process of finding causes of performance deviations and explaining the achieved performance. Diagnosing the performance is important because to some extent, management often claims to know the causes for performance deviations (Wibisono 1998). They can offer numerous explanations for the observed gap between the actual performance and the performance target. According to Stoop (1996), the danger of qualitative explanations regarding the deviations of performance is that it is possible that the presumed causes are not all the causes that explain the observed performance gap. In this case, there are other causes that have not been determined yet. For this reason, it is impor- tant to have knowledge of the linkages among different performance variables. Secondly, if the result of the diagnosis produces veritable causes, one can use this information to reinforce the intuition. Thirdly, due to all kinds of changes in the shop floor or its environment, there is a danger that problems are solved only by using past experiences whereas new factors may have arisen.

Action Plan is concerned with identifying actions that need to take place if performance proves to be either satisfactory or unsatisfactory. There are two different aspects for the improvement of actions: strategic and technical issues (Skinner 1996). The strategic aspect is dealing with decision-making in the higher level of management and in the long-term policy, especially in the policy of improvement resources. For instance, if it is found that inadequate resources are thwarting the company, the need for new resource capabilities is imminent.

\section{The Conceptual Model of the Hybrid KBPMS}

The hybrid PMS Framework introduced in Section 2 can be visualized from strategic and operational structures, as graphed in Figure 2. Figure 2 is a clearer interpretation of how the hybrid PMS framework has been actually developed as a hybrid KBPMS expert system model.

Surely, there are links among performance measures at one level with those at other levels. Company perfor- 
Figure 2. Showing the Hybrid KBPMS Model Framework

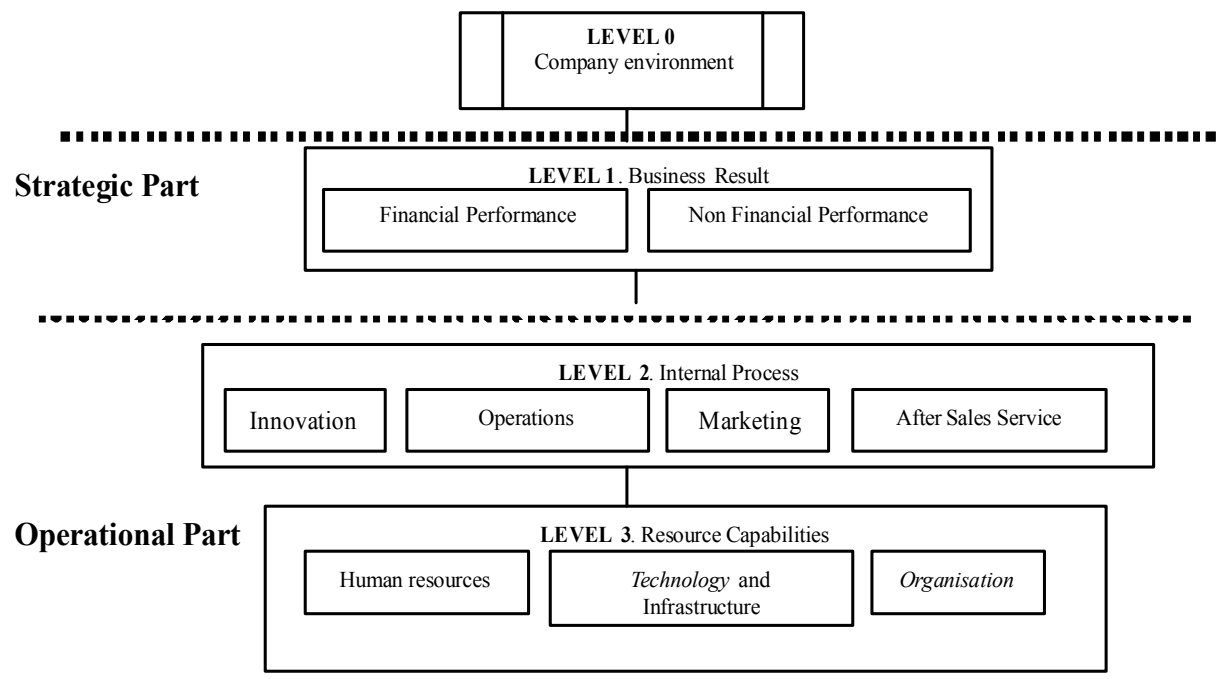

mance in the Business Result Perspective (Level 1), for example, is influenced by the performance in the Internal Processes Perspective (Level 2). Performance in Level 2 is affected by performance in Level 3 (Resource Capability Perspective). It can be observed that the company's profitability is influenced by product quality, while the product quality per se will increase if the employer possesses excellent capabilities. Hence, there is an inter-relation (across and below) of factors that affect the performance of a company, which should be taken into account in the KBPMS model. The following description elaborates on Figure 2.

Level 0-Company Environment. The Company Environment Module (Level 0 ) determines the particular environment in which the company is operat- ing. Since different company environments require different performance standards and improvement strategies, it is therefore a crucial stage to identify and map the company's environment to ensure that the performance diagnosis is valid, reliable and factual. The information needed in this module is: the type of industry, the number of employees, the age of company, the age of industry, competitors and business life cycle.

The industry information is beneficial to classifying a firm into a certain group of appropriate benchmarks based on the products or services produced. This classification is based on the reasoning that a certain type of industry has its own competitive priorities and special performance standard. In this module, the types of industries and their respective products 
Wibisono \& Khan -The ConceptualFramework of a Knowledge-Based Performance Management System

are based upon definitions and classifications proposed by Willmot and McCarthy (2001).

The information about company age, industry age, and competitors is crucial to positioning the company relative to the competitors and the industry age itself. This information is the starting point for mapping the current status or circumstances relative to the competitors such that the improvement programs can be determined.

Business life cycle influences the company in determining its company strategy. The most practical approach in monitoring the stage of the life cycle of a company can be conducted through monitoring its investment activities in a certain period. Kaplan and Norton (1996) classify the industry life cycle based on the investment activities.

Level 1 - Business Perspective. This level covers the first strategic part of the KBPMS model. Financial and nonfinancial objectives serve as the foci of all businesses in the world. Profit maximization, the maximization of return on capital, the maximization of shareholder wealth, the fulfillment of government regulations, customer satisfaction, survival and growth are some of the most important objectives of a firm. It is therefore crucial to consider these business parameters in any PMS. In the KBPMS model, The Business Perspective Module assesses the company's financial and non-financial performances through specific performance criteria. The financial and non-financial performances serve as the foci for the objectives and measures of Internal Processes Perspective.

Level 2 - Internal Processes Perspective. Internal processes have been a focus of improvement in competitiveness for a long time. Even traditional PMS systems are usually focused on controlling and improving existing departments which are not only separated from the operational activities of other departments, but also have no relationship with the other programs (Neely and Bourne 2000). Since an internal process represents the effectiveness and efficiency of internal operations performance, it is thus important to manage the performance rigorously. Four of the most important performance parameters in the Internal Process Perspective to be assessed are Innovation, Operations, Marketing and Post-Sales Services, with each aspect consisting of several performance subvariables.

Level 3 - Resource Capability Perspective. An organization must also invest in human resources, technology and infrastructure, and improve its organizational practices if they are to achieve ambitious long-term financial growth objectives and other non-financial performances. In the proposed KBPMS model, this infrastructure is labelled as the Resource Capability Perspective. There are three main categories of resources to be assessed: Human Resources, Technology and 
Infrastructure, and Organization, within which there are a number of sub-categories.

The discussion above has described in details the KBMPS model and its structure. The following section describes the GAP and AHP aspects, which are imbedded in the hybrid KBPMS.

\section{The Gauging Absences of Prerequisites (GAP) Methodology}

The assessment of company performance in the Hybrid KBPMS model is conducted through sequential questions that measure both qualitative and quantitative information on the company performance in each level based on the Gauging Absences of Prerequisites (GAP) analysis. GAP analysis is used to determine the disparity between the essential or desirable prerequisites and what actually exists in the organization within each module of the KBPMS model. This analysis is utilized to identify likely problem areas, which must be addressed by the management if an effective implementation is to be accomplished. The mechanism of GAP analysis is carried out through the responses of the users to the questions provided in the hybrid KBPMS model. The problems highlighted for each negative reply is categorized under the following headings in descending order of importance (Kochhar et al. 1991).

Category 1: This indicates a serious problem, which should and can be resolved in the short run, and the resolution of the problem is quitelikely to providereal short-term benefits

Category 2: This indicates a serious problem which is likely to have prerequisites, and is thus better dealt with as part of an appropriate and logical improvement and implementation plan

Category 3: This is not a serious problem, but can be dealt with right now. If resolved, it is likely to yield shortterm benefits

Category 4: This is not a serious problem. Although it could be dealt with right now, it is unlikely to yield shortterm benefits. Therefore, it should only be dealt with if it is a prerequisite for other things

Category 5: This is not really a good or bad point itself; the questions associated with this category are primarily asked to identify certain situations in the environment which, upon subsequent probing by succeeding questions, may well reveal problems

When the users select the required topic, they will be presented with a description of the selected GAP analysis topic, such as the high level Financial and Non-Financial Information 
Wibisono \& Khan -The Conceptual Framework of a Knowledge-Based Performance Management System

Table 2. High Level Issue Financial and Non-Financial Information

\begin{tabular}{l} 
High level issue: Financial and Non Financial Information \\
\hline 1. Objective \\
This module will assess a company's financial and non financial level along specific performance criteria. \\
The financial and non financial objectives serve as the focus for the business objectives and measure the \\
company's overall performance. \\
2. Reasons \\
- Every business measures financial and nonfinancial performance since it indicates how the company \\
runs, survives and competes as well as indicatinghow the company gives financial and non financial \\
valueadded to the stakeholders (Wibisono 2003) \\
- The nonfinancial performance from the site of government, customer, community arenow alsoplay as \\
important role \\
3. Variables to be assessed \\
Four financial ratios (leverage, liquidity, profitability and return on investment) and three non financial \\
parameters (customer, governmentand community) will be assessed in this module
\end{tabular}

Table 3. Customer Loyalty Sub-module

QUESTIONS: CUSTOMER LOYALTY

Q1.1 Did you measure your customer loyalty?

(Please tick)

OYES ONO (Bad Point: Problem Category 1)

EXPLANATION:

- Customer loyalty measures level of loyalty of customer to any products or services produce by company. It reflects how competitive the company's product and services are in the market and indicates the customer willingness to buy any products or services their give.

- It is therefore, crucial to measure a company's customer loyalty relative to their products or services. Having no performance measure on customer loyalty is categorised as Bad Point Problem Category 1 since the company has no clear idea of its business market and behaviour of its customers.

\begin{tabular}{|l|}
\hline Explanation \\
\hline
\end{tabular}

issues (Table 2). After the introduction screen, the users will be directed through the questions (which in essence are the rules developed for the $\mathrm{KB}$ expert system) in a stepwise manner (Table 3). Depending upon the users' responses to a particular question, different questions may be asked subsequently. The users have been provided with the facility to see the explanations (additional $\mathrm{KB}$ ) created to assist in deciding on the answer for the question.

A summarized result, as shown in Table 4, will be displayed in the end of each GAP analysis topic. The result shown consists of the total number of questions asked, the number of good points, the number of bad points (along with their Problem Category types), 
Gadjah Mada International Journal of Business, September-December 2010, Vol.12, No. 3

Table 4. Results Summary for Customer Loyalty Sub-module

\begin{tabular}{ccccc}
\hline \multicolumn{3}{c}{ SUMMARISED RESULTS FOR GAP-ANALYSIS } \\
Customer Loyalty & \multicolumn{3}{c}{ Number of Good Points: 3} \\
\hline Number of question asked: 15 & & \multicolumn{3}{c}{ Number of Bad Points: 12} \\
Category 1 & Category 2 & Category 3 & Category 4 & Category 5 \\
3 & 5 & 2 & 2 & 0
\end{tabular}

COMMENTS: Category 1 Bad Points

Q1.1 You did not measure your customer loyalty to the main customer

Q1.5 Your customer loyalty is $<25 \%$

Q1.7 Your customer loyalty decreased continuously in the last 3 years.

Press Recommendation button below to indicate possible solutions to the issues highlighted by the GAP Analysis.

Recommendation

Next

comments and recommendations on the GAP analysis topic. It may be noted that only the negative (Bad Points) are categorized into problem types. The reason for this is that the $\mathrm{KB}$ system's main aim is to identify the missing prerequisites so that the performance measurement can include the recommended actions for improvement.

\section{The Analytical Hierarchy Process (AHP) Methodology}

The selection of the most suitable improvement priorities is a multi-attribute and complex problem. It requires the development of tools to address both qualitative and quantitative parameters. The AHP methodology is one of the most powerful methods employed to deal with these kinds of problems (Razmi et al. 1998). The application of the AHP not only provides the tool to weigh the factors, but also confirms the correctness and in- tegrity of the comparison of the factors made by the users.

AHP has been applied to several decision problems, e.g., investment appraisal, human resources evaluation, project selection, and vendor rating, to name but a few. However, little attention has been given so far to the application of the AHP to performance management. The steps of implementing AHP in this KBPMS model follows the guidance given by Saaty (1980); however, the following list gives an outline of the process:

- State the problem,

- Identify criteria that influence the behavior of the problem,

- Structure the hierarchy of the criteria, sub-criteria, alternatives, and the properties of alternatives,

- Prioritize the primary criteria with respect to their impacts on the overall objective called the focus,

- State the question for pair-wise comparison clearly above each matrix, 
Wibisono \& Khan -The Conceptual Framework of a Knowledge-Based Performance Management System

\section{Figure 3 Showing the AHP Structure for KBPMS Model}

\section{LEVELS}

\section{Business Result Perspective}

II. Internal Processes

Perspective

III. Resource Capability Perspective

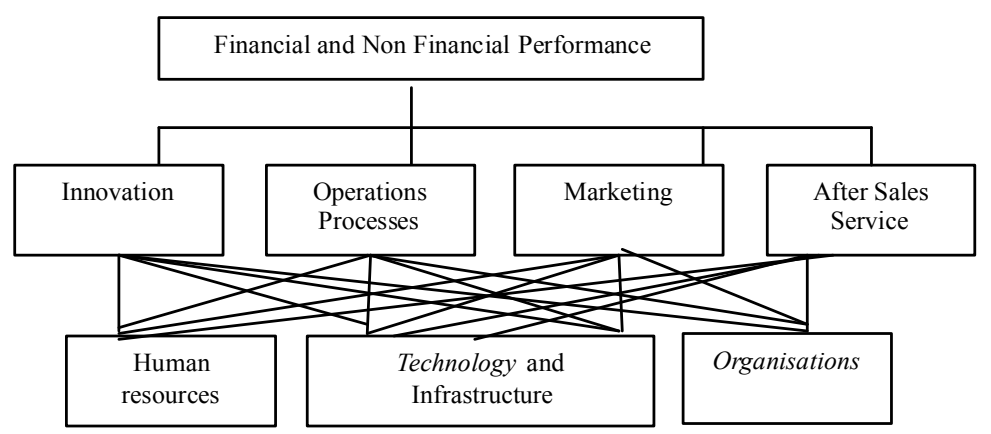

- Prioritize the sub-criteria with respect to the criteria,

- Enter pair-wise comparison judgments and force their reciprocals,

- Calculate priorities by adding the elements of each column and dividing each entry by the total of the column. Average over the rows of the resulting matrix and get the priority vector.

Referring to the structure of KBPMS model as illustrated in Figure 2 , and considering the steps of implementation of the AHP stated above, the AHP hierarchy embedded within the KBPMS model is shown in Figure 3.

From Figure 3, it can be observed that the AHP is a three-level hierarchical structured model, which is able to analyze the given company competitiveness based on the focus on the Business Result Perspective Performance. The Business Result Perspective Performance is influenced by the company performance in the Internal Processes Perspective, which consists of Innovation, Operations, Marketing and Post-Sales Services. The root alternatives that should be improved to increase the performance in the Internal Process Perspective are Human Resources, Technology and Infrastructure, and Organization.

The pair-wise comparisons start from Level 2 of the AHP: Innovation (I), Operations Processes (O), Marketing (M), and Post-Sales Services (A). Data on these comparisons are transferred directly from the process of GAP analysis embedded in the KBPMS model. This means that the AHP model decides on which one of these four factors (I, O, M, A) should be in the priority of improvement to increase the company's competitiveness in the Business Perspective. This module is designed to determine the most suitable improvement priorities of competitiveness for a given circumstance based on the interactive users' answers to each sub-module, thus assisting in the decision-making process. 
Gadjah Mada International Journal of Business, September-December 2010, Vol.12, No. 3

The combination between the GAP analysis and the AHP approach needs a transferred process of scale. It has been explained earlier that in the GAP analysis, there are five Problem Categories for each performance con-

\section{Table 5. Results of Simulation for Internal Process Perspective}

\begin{tabular}{|c|c|c|c|c|c|c|c|c|c|}
\hline \multirow[t]{2}{*}{ Sub-Module } & \multirow[t]{2}{*}{ Aspect } & & \multirow{2}{*}{$\begin{array}{l}\text { Number of } \\
\text { questions }\end{array}$} & \multirow{2}{*}{$\begin{array}{l}\text { Good } \\
\text { Point }\end{array}$} & \multicolumn{5}{|c|}{ Problem Category Achieved } \\
\hline & & & & & 1 & 2 & 3 & 4 & 5 \\
\hline \multirow[t]{8}{*}{ Innovation } & \multirow[t]{2}{*}{ Commitment } & Top management on Innovation & 6 & 3 & 0 & 1 & 2 & 0 & 0 \\
\hline & & Budget allocation & 3 & 0 & 0 & 0 & 1 & 2 & 0 \\
\hline & \multirow[t]{4}{*}{ Programmes } & Content of programmes & 12 & 0 & 1 & 11 & 0 & 0 & 0 \\
\hline & & $\begin{array}{l}\text { Employee participation on programmes } \\
\text { development }\end{array}$ & 18 & 1 & 1 & 3 & 4 & 0 & 9 \\
\hline & & Project manager existence \& reliability & 23 & 11 & 0 & 0 & 0 & 0 & 12 \\
\hline & & Programmes reliability & 35 & 13 & 11 & 6 & 1 & 4 & 0 \\
\hline & \multirow{2}{*}{$\begin{array}{l}\text { Programmes } \\
\text { achievement }\end{array}$} & Innovation & 17 & 0 & 0 & 2 & 2 & 13 & 0 \\
\hline & & TOTAL & 114 & 28 & 13 & 23 & 10 & 19 & 21 \\
\hline \multirow{8}{*}{$\begin{array}{l}\text { Manufacturing } \\
\text { process }\end{array}$} & \multirow{2}{*}{ Commitment } & Top management & 6 & 6 & 0 & 0 & 0 & 0 & 0 \\
\hline & & Budget allocation & 3 & 0 & 0 & 3 & 0 & 0 & 0 \\
\hline & \multirow[t]{4}{*}{ Programmes } & Content of programmes & 18 & 3 & 8 & 7 & 0 & 0 & 0 \\
\hline & & $\begin{array}{l}\text { Employee participation on f programmes } \\
\text { development }\end{array}$ & 19 & 0 & 1 & 4 & 5 & 0 & 9 \\
\hline & & Project manager existence $\&$ reliability & 23 & 9 & 2 & 0 & 0 & 0 & 12 \\
\hline & & Reliability of the programmes & 19 & 14 & 1 & 3 & 1 & 0 & 0 \\
\hline & \multirow[t]{2}{*}{$\begin{array}{l}\text { Programmes } \\
\text { achievement }\end{array}$} & Manufacturing process & 42 & 6 & 36 & 0 & 0 & 0 & 0 \\
\hline & & TOTAL & 130 & 38 & 48 & 17 & 6 & 0 & 21 \\
\hline \multirow[t]{8}{*}{ Marketing } & \multirow[t]{2}{*}{ Commitment } & Top management & 6 & 6 & 0 & 0 & 0 & 0 & 0 \\
\hline & & Budget allocation & 3 & 0 & 3 & 0 & 0 & 0 & 0 \\
\hline & \multirow[t]{4}{*}{ Programmes } & Content of programmes & 11 & 9 & 0 & 2 & 0 & 0 & 0 \\
\hline & & $\begin{array}{l}\text { Employee participation on programmes } \\
\text { development }\end{array}$ & 18 & 9 & 0 & 0 & 0 & 0 & 9 \\
\hline & & Project manager existence \& reliability & 23 & 11 & 0 & 0 & 0 & 0 & 12 \\
\hline & & Reliability of the programmes & 25 & 15 & 3 & 7 & 0 & 0 & 0 \\
\hline & \multirow[t]{2}{*}{$\begin{array}{l}\text { Programmes } \\
\text { achievement }\end{array}$} & Marketing & 18 & 9 & 3 & 3 & 3 & 0 & 0 \\
\hline & & TOTAL & 104 & 59 & 9 & 12 & 3 & 0 & 21 \\
\hline \multirow{9}{*}{$\begin{array}{l}\text { Post Sales } \\
\text { service }\end{array}$} & \multirow[t]{2}{*}{ Commitment } & Top management Service & 6 & 0 & 1 & 3 & 2 & 0 & 0 \\
\hline & & Budget allocation & 3 & 0 & 3 & 0 & 0 & 0 & 0 \\
\hline & \multirow[t]{4}{*}{ Programmes } & Content of Programmes & 10 & 0 & 10 & 0 & 0 & 0 & 0 \\
\hline & & $\begin{array}{l}\text { Employee participation on programmes } \\
\text { development }\end{array}$ & 18 & 0 & 9 & 0 & 0 & 0 & 9 \\
\hline & & Project manager existence \& reliability & 22 & 0 & 11 & 0 & 0 & 0 & 12 \\
\hline & & Reliability of the programmes & 19 & 2 & 9 & 0 & 0 & 0 & 0 \\
\hline & \multirow{3}{*}{$\begin{array}{l}\text { Programmes } \\
\text { achievement }\end{array}$} & Post Sales Service Achievement & 10 & 0 & 10 & 0 & 0 & 0 & 0 \\
\hline & & TOTAL & 88 & 2 & 53 & 3 & 2 & 0 & 21 \\
\hline & & GRAND TOTAL & 436 & 134 & 123 & 55 & 21 & 19 & 84 \\
\hline
\end{tabular}


Wibisono \& Khan -The Conceptual Framework of a Knowledge-Based Performance Management System

Table 6. AHP Results for Internal Process Perspective

\begin{tabular}{|c|c|c|c|c|c|}
\hline & Innovation & $\begin{array}{l}\text { Manufacturing } \\
\text { Process }\end{array}$ & Marketing & Post Sales Service & Priority Vector \\
\hline Innovation & 1 & $1 / 2$ & 2 & $1 / 5$ & 0.124 \\
\hline Manufacturing Process & 2 & 1 & 4 & $1 / 3$ & 0.237 \\
\hline Marketing & & $1 / 4$ & 1 & $1 / 6$ & 0.071 \\
\hline Post Sales Service & 5 & 3 & 6 & 1 & 0.567 \\
\hline
\end{tabular}

dition assessed, while the AHP approach (Saaty 1980) provides nine Intensity of Importance to be implemented for each sub-module level. Thus, the five-level scale of the GAP methodology needs to be scaled (transferred) to the nine-scale AHP methodology, and this has been described in details in Wibisono (2002a, 2002b).

It needs to be reiterated that the KB-GAP analysis provides the priority actions required internally to each and every sub-module (in terms of Problem Categories) contained within the KBPMS model, whereas the AHP outputs provide the prioritized actions between (external to) the sub-modules. Accordingly, the users can obtain information on which main modules/ sub-modules need to be prioritized for improvement through the AHP methodology, and then what precisely needs to be done within each of these identified modules/sub-modules with respect to eliminating the Problem Categories through the earlier exercise carried out by the KB-GAP aspect of the KBPMS model, thereby providing detailed and practical information for assisting in the decision-making process.

Table 5 illustrates an example of simulation results that have been taken for the Internal Process Perspective. The table shows that the company still has big problems since there are about 30 percent category I encountered, indicating that these problems need to be solved first before the company will be able to improve other sectors.

From the AHP factor, it can be seen from Table 6 that the company puts post-sales services as the biggest priority to improve compared to innovation, manufacturing processes, and marketing.

\section{Conclusion}

This paper has described the details of the KBPMS model, which is a novel and improved methodology compared to the previous PMS frameworks. The proposed model has introduced new aspects that have not been covered by previous researchers, especially in terms of the implementation of a KB expert system approach, and the combination of GAP and AHP analysis in an integrated model, as a supporting decision-making tool.

In the procedures of designing PMS, this study has developed a conceptual model that consists of three stages considered in designing the 
KBPMS: (1) Basic Information, (2) Core of Performance Management and (3) Mechanisms of Performance Management. Every stage has several aspects that play an important role, and they have been explained in details.

The proposed KBPMS can be visualized from strategic and operational structures. In the strategic part, there are two modules, namely Company Environment and Business Result Perspective. The Company Environment Module determines the particular environment in which the company operates. The Business Result Perspective Module analyses financial and non-financial performances. In the operational part, two modules, i.e., Internal Process Perspective and Resource Capability Perspective, are developed, and in each module there are sub-modules and performance variables that have been discussed in details.

The proposed KBPMS model implements the GAP analysis, the benchmarking process and the AHP approach in an integrated performance management system. The process of translating Problem Category in the GAP analysis for each assessed performance into the Intensity of Importance in the AHP approach is conducted through consistent mechanism and weighting processes. The hybrid KBPMS model provides a detailed and accurate decision-making tool for the improvement of the PMS, and accordingly the performance management in a manufacturing environment.

From the simulation results and discussion with practitioners in Indonesian companies, it is noted that this model is simpler in implementation because the detailed model has been provided with supporting knowledgebased interactive software. It also can encourage users to increase and understand their knowledge related to their companies' performances by updating state-of-the-art techniques into the software provided that could help in the decision-making.

\section{References}

Centre of Business Performance. 1999. http://www.cranfield.ac.u/som/cbp.

Clark, B. H. 2000. Assessing marketing performance: History and challenges. International Journal of Business Performance Management 2 (1/2/3): 42-55.

Cross, K. F., and R. L. Lynch. 1989. The 'SMART' way to define and sustain success. National Productivity Review (winter): 23-33.

Dixon, J. R., A. J. Nanni, and T. E. Vollman. 1990. The New Performance ChallengeMeasuring Operation for World-Class Competition. 1rwin, Homewood, IL.

Gosselin, M. 2005. An empirical study of performance management in manufacturing firms. International Journal of Productivity and Performance Management 54 (5/6): 419-437.

Hayes, R. H., and G. P. Pisano. 1996. Manufacturing strategy: At the intersection of two paradigm shifts. Production and Operation Management 5 (1) (spring): 25-41. 
Wibisono \& Khan -The ConceptualFramework of a Knowledge-Based Performance Management System

Hronec, S. M. 1993. Vital Signs : Using Quality, Time, and Cost Performance Managements to Chart Your Company's Future. New York: Amacom.

Ingle, S. 2000. Realigning performance measures: Case study in Irish industry. International Journal of Business Performance Management 2 (1/2/3): 124-136.

Kaplan, R. S., and D. P. Norton. 1996. The Balanced Scorecard: Translating Strategyinto Action. Boston, MA: Harvard Business School Press.

Khan, M. K., and D. Wibisono. 2008. A hybrid knowledge-based performance measurement system. Business Process Management Journal 14: 129-146. Emerald Group Publishing Limited.

Kochhar, A. K., A. K. Suri, and R. Hather. 1991. Design and implementation of a general purpose knowledge-based gap analysis system with particular reference to the implementation of effective material requirements planning systems. Proceedings of the I Mech E, Effective CADCAM91: 129-134.

Letza, S. R. 1997. A collected of publications on performance Management. Unpublished PhD Thesis. University of Bradford - UK.

Ljungberg, A. 1994. A Management of service and quality in the order process. Unpublished Thesis. Lund University, Belgium.

Maskell, B. H. 1991. Performance Management for World Class Manufacturing. Cambridge MA: Productivity Press.

Mediatma, A. U., and D. Wibisono. 2006. Business intelligence scenario of bank X in improving product's performance. Proceeding International Conference on Technology and Operations Management. Bandung.

Medori, D. and D. Steeple. 2000. A framework for auditing and enhancing performance Management systems. International Journal of Operations and Production Management: $520-533$.

Medori, D. 1998. The development and implementation of an integrated performance Management framework. Proceedings of Performance Management - Theory and Practice: International Conference: 639-46. University of Cambridge, Cambridge.

Neely, A. and M. Bourne. 2000. Why Management initiatives fail. Measuring Business Excellent 4 (4): 3-6.

Neely, A., C. Adams, and M. Kennerly. 2002. The Performance Prism The Scorecard for Measuring and Managing Business Success. London: Prentice Hall.

Razmi, J., H. Rahnejat, and M. K. Khan. 1998. Use of analytic hierarchyprocess approach in classification of push, pull and hybrid push-pull system for production planning. International Journal of Operations and Production Management 18 (11): 11341151.

Saaty, T. L. 1980. The Analytical Hierarchy Process. New York: McGraw-Hill.

Schmenner, R. W. and T. E. Vollman. 1994. Performance measures: Gaps, false alarms and the 'usual suspects. International Journal of Operations and Production Management: 58-67. 
Gadjah Mada International Journal of Business, September-December 2010, Vol.12, No. 3

Sellenheim, M. R. J. I. 1991. Case company: Performance Management. Management Accounting (Septeber): 50-53.

Skinner, W. 1969. Manufacturing: missing link in corporate strategy. Harvard Business Review (May-June): 136-45.

Skinner, W. 1996. The Focused factory: New approach to managing manufacturing sees our productivity crisis as the problem of 'how to compete.' Harvard Business Review (May-June).

Sousa, G. W. L., L. C. R. Carpinetti, R. L. Groesbeck, and E. Van Aken. 2005. Conceptual design of performance management and management systems using a structured approach. International Journal of Productivity and Performance Management 54 (5/6): 385-39.

Stoop P.P.M. 1996. Performance Management in Manufacturing: A method for short-term performance evaluation and diagnosis. PhD theses. Technische Universiteit Eindhoven, Holland.

Wibisono, D. 2007. Prototype design of performance management support systems. Proceeding Asia Pacific Conference on Operations Management Systems. Bali.

Wibisono, D. 1998. A study of manufacturing effectiveness. Unpublished Master Thesis. RMIT-Australia.

Wibisono, D. 2003. A knowledge based approach in the design of performance measurement systems in the manufacturing environment. PhD Dissertation. University of Bradford, the United Kingdom.

Wibisono, D. and M. Khan. 2002a. A framework of performance management system design for manufacturing: Advances in business paradigms and supporting technologies. Proceedings of the $18^{\text {th }}$ International Conference on CAD/CAM, Robotics and Factories of the Future (3-5 July). Porto, Portugal.

Wibisono, D. and M. Khan. 2002b. A hybrid knowledge-based/analytic hierarchy process (AHP) performance management system for manufacturing: Advances in business paradigms and supporting technologies, Proceedings of the $18^{\text {th }}$ International Conference on CAD/CAM, Robotics and Factories of the Future (3-5 July). Porto, Portugal.

Wibisono, D. 2006. Quality assurance for university. MBA-ITB Business Review 1 (May).

Wibisono, D., H. Mee Hoa, and P. Untea. 2006. Design of corporate performance management system: Case study at PT. X in Indonesia. Proceeding International Conference on Technology and Operations Management. Bandung.

Willmott, P., and D. McCarthy. 2001. TPMA Route to World-Class Performance. Oxford: Butterworth-Heinemann.

Zairi, M. 1998. Effective Management of Benchmarking Projects: Practical Guidelines and Examples of Best Practice. Oxford: Butterworth-Heinemann.

Zairi, M. and S. Letza. 1994. Performance Management: a challenge for total quality and the accounting professions. Asia Pacific Journal of Quality Management 3 (2): 2641. MCB University Press. 
